J. Lake Sci. (湖泊科学), 2014, 26(5): 743-750

http://www. jlakes. org. E-mail : jlakes@niglas.ac.cn

(C) 2014 by Journal of Lake Sciences

\title{
太湖不同生态类型湖区浮游甲壳动物群落结构季节变化比较
}

\author{
王 渘 $^{1}$, 杨桂军 $^{1 * *}$, 秦伯强 $^{2}$, 张艳晴 $^{1}$, 许慧萍 ${ }^{1}$, 王玉兵 ${ }^{1}$ \\ (1: 江南大学环境与土木工程学院,无锡 214122) \\ (2: 中国科学院南京地理与湖泊研究所湖泊与环境国家重点实验室,南京 210008)
}

摘 要: 水体富营养化会对整个水生态系统产生重要影响. 为了解太湖富营养化对浮游甲壳动物群落结构的影响, 于 2012 年 3 月至 2013 年 2 月对太湖 3 个典型湖区一一藻型湖区 (梅梁湾)、草型湖区 (胥口湾) 和强扰动湖区 (湖心区) 开展 浮游甲壳动物群落结构季节变化比较研究. 3 个湖区中, 湖心区营养水平最高, 胥口湾最低. 梅梁湾浮游甲壳动物密度和 生物量最高, 其次是湖心区, 胥口湾最低. 梅梁湾、湖心区和胥口湾的浮游甲壳动物年平均密度分别为 199 、150 和 91 ind. $/ \mathrm{L}$, 年平均生物量分别为 $1.950 、 1.557$ 和 $0.743 \mathrm{mg} / \mathrm{L}$. 在整个研究期间, 梅梁湾、胥口湾和湖心区的浮游甲壳动物 种类数分别为 $13 、 11$ 和 $11 ; 3$ 个湖区的浮游甲壳动物优势种均为中华窄腹剑水蚤和简弧象鼻溞,其中中华窄腹剑水蚤在 梅梁湾、胥口湾和湖心区的年平均密度分别为 $57 、 25$ 和 36 ind. / L , 简弧象鼻泽在 3 个湖区的年平均密度分别为 $40 、 22$ 和 32 ind. /L. 胥口湾浮游甲壳动物生物多样性指数显著低于梅梁湾和湖心区. 相关分析表明,浮游甲壳动物密度与叶绿素 $\mathrm{a}$ 浓度呈极显著正相关. 研究表明,同一湖泊不同生态类型湖区浮游甲壳动物会对水体富营养化产生不同的生态响应.

关键词: 太湖;梅梁湾;胥口湾;浮游甲壳动物;群落结构;季节变化

\section{A comparative study on the seasonal variations of community structure of crustaceans in different ecological areas in Lake Taihu}

WANG Ying $^{1}$, YANG Guijun ${ }^{1}$, QIN Boqiang ${ }^{2}$, ZHANG Yanqing $^{1}$, XU Huiping ${ }^{1} \&$ WANG Yubing ${ }^{1}$

(1: School of Environment and Civil Engineering, Jiangnan University, Wuxi 214122, P. R. China)

(2: State Key Laboratory of Lake Science and Environment, Nanjing Institute of Geography and Limnology, Chinese Academy of Sciences, Nanjing 210008, P. R. China)

\begin{abstract}
Eutrophication brings important influence on water ecosystem. In order to understand the influence of eutrophication on the community structure of crustaceans in Lake Taihu, a comparative study on the seasonal variations of crustaceans community structure of three typical lake areas in Lake Taihu, including algae-dominated lake area (Meiliang Bay), macrophytes-dominated lake area (Xukou Bay) and strongly disturbed lake area (the lake center), was undertaken from March 2012 to February 2013. The trophic level was the highest in the lake center and the lowest in Xukou Bay. The annual average abundance and biomass of crustaceans were 199 ind. /L and $1.950 \mathrm{mg} / \mathrm{L}$ in Meiliang Bay, 91 ind. $/ \mathrm{L}$ and $0.743 \mathrm{mg} / \mathrm{L}$ in Xukou Bay, and 150 ind. $/ \mathrm{L}$ and $1.557 \mathrm{mg} / \mathrm{L}$ in the lake center, respectively. Thirteen crustaceans species were identified in the Meiliang Bay, and 11 in Xukou Bay and the lake center, respectively. The dominant species of crustaceans were Limnoithona sinensis and Bosmina coregoni in the three lake areas. The annual average abundance of Limnoithona sinensis were 57, 25 and 36 ind. /L, and the annual average abundance of Bosmina coregoni were 40, 22 and 32 ind. /L in Meiliang Bay, Xukou Bay and the lake center, respectively. The biological diversity of crustaceans in Xukou Bay was significantly lower than that in Meiliang Bay and the lake center. Correlation analysis indicated positive relationships between abundance of crustaceans and the concentration of chlorophyll-a. It was also found that response of crustaceans to eutrophication were different in different ecological areas in Lake Taihu.
\end{abstract}

Keywords: Lake Taihu; Meiliang Bay; Xukou Bay; crustaceans; community structure; seasonal variation

* 国家水体污染控制与治理科技重大专项项目(2012ZX07101-013-03，2012ZX07503-002)、国家自然科学基金项目 (41101053) 和国家自然科学基金重点项目 (41230744) 联合资助. 2013-09-04 收稿;2013-12-28 收修改稿. 王 颖(1989 ), 女, 硕士;E-mail : wangying8899@ 126.com.

** 通信作者; E-mail:yanggj1979@ 163.com. 
水体富营养化通常会对整个水生食物网结构产生重大的影响, 包括浮游植物、浮游动物、水生植物和鱼 类群落 ${ }^{[1-3]}$. 浮游甲壳动物是淡水生态系统的重要组成部分, 一方面, 浮游甲壳动物主要以浮游植物为食 ${ }^{[4]}$, 同时又能摄食细菌 ${ }^{[5-6]}$ 、原生动物 ${ }^{[7-8]}$; 另一方面, 浮游甲壳动物又是一些鱼类优良的食物 ${ }^{[9-10]}$. 所以, 在水生 生物食物链中, 浮游甲壳动物在低营养级和高营养级之间起着重要的桥梁作用. 同时, 浮游甲壳动物也是水 体营养状态良好的指示类群.

大量研究表明, 水体富营养通常会导致水体中浮游甲壳动物的数量和生物量增加 ${ }^{[11-12]}$. 氮、磷营养盐的 大量输人是导致水体富营养化的主要因素, 营养盐的大量增加会引起水体浮游植物群落结构的改变, 从而 间接影响浮游甲壳动物的群落结构. 然而, 除了氮、磷营养盐以外, 水体中的其它环境因素 (如水温、水动力 扰动、 $\mathrm{pH} 、$ 细菌、鱼类、水生植物等) 也会对浮游甲壳动物群落结构产生重要的影响. 不同生态类型的湖泊 (包括以蓝藻为特征的藻型湖泊, 以水生植物为特征的草型湖泊及以强烈风浪扰动为特征的扰动型湖泊 等), 其浮游甲壳动物群落结构特征往往不同, 浮游甲壳动物对不同的生态类型湖泊的水体富营养可能会产 生不同的响应. 有关不同生态类型湖泊水体富营养化对浮游甲壳动物群落结构影响的研究已有较多报 道 ${ }^{[13-15]}$, 这些研究往往是针对不同湖泊进行的, 而针对同一个富营养湖泊的不同生态类型湖区进行浮游甲 壳动物群落结构的比较研究尚不多见 ${ }^{[16-18]}$. 开展同一富营养湖泊不同生态类型湖区浮游甲壳动物群落结构 的比较研究, 有利于人们更加深人地认识水体富营养化对水生态系统的影响, 尤其是对浮游甲壳动物群落 结构的影响.

太湖是我国五大淡水湖泊之一, 从 1970s 末、1980s 初开始, 富营养化日趋严重. 梅梁湾是太湖北部一个 较大的湖湾, 富营养化水平较高, 每年的 5-11 月都会出现大量的蓝藻水华 ${ }^{[19]}$, 属于典型的藻型湖区; 胥口 湾是太湖东南部的一个湖湾, 水质清澈, 水草茂盛, 属于典型的草型湖区; 湖心区位于太湖的中心区域, 风浪 扰动强烈, 属于扰动型湖区. 本文以太湖梅梁湾、胥口湾及湖心区作为研究对象, 开展了一周年的浮游甲壳 动物群落结构调查研究, 旨在比较太湖 3 个不同生态类型湖区浮游甲壳动物的群落结构特征, 以探讨浮游 甲壳动物对同一湖泊不同生态类型湖区水体富营养化的不同响应及其可能机制.

\section{1 材料与方法}

\section{1 采样点的设置}

2012 年 3 月至 2013 年 2 月, 在梅梁湾、胥口湾以及湖心区共布设 3 个采样点, 进行浮游甲壳动物和水 体理化因子的现场调查.

\section{2 样品的采集与处理}

样品每月采集 1 次, 用 $5 \mathrm{~L}$ 有机玻璃柱状采水器采集水下 $25 、 75 、 125 \mathrm{~cm}$ 处湖水, 混匀后用 $48 \mu \mathrm{m}$ 的浮游 生物网过滤, 并将浮游甲壳动物装人 $50 \mathrm{ml}$ 的方形塑料瓶中. 每次采样共取 2 次, 第 1 次作定性分析, 保存活 体; 第 2 次作定量分析, 取 3 个平行样, 立即加人 $4 \%$ 的甲醛固定. 用柱状采水器采集湖水混匀, 取 $1000 \mathrm{ml}$, 带回实验室后分析水样化学指标 (总氮、总磷、氨氮) 和叶绿素 $\mathrm{a}(\mathrm{Chl} . \mathrm{a})$ 浓度 ${ }^{[20]}$, 并在现场测定水深、水温、 透明度、 $\mathrm{pH}$ 、溶解氧和电导率.

\section{3 浮游甲壳动物的分类、计数}

参考文献 [21-25]在显微镜下进行浮游甲壳动物的分类、计数. 在种群密度很高时, 用分小样的方法抽 样计数. 具体步骤是: 将采集的 $50 \mathrm{ml}$ 样品充分摇匀后用宽口吸管吸取 $5 \mathrm{ml}$, 注人浮游甲壳动物计数框中, 计 数 3 片取其平均值, 然后乘以稀释倍数即为单位体积中浮游甲壳动物的数量.

\section{4 生物量的计算}

桡足类的体积由相近的几何形状换算成生物量 ${ }^{[26]}$ (由于有机体的密度比水的密度稍大, 可近似取值为 $1 \mathrm{mg} / \mathrm{mm}^{3}$ ). 枝角类的生物量根据体长-体重回归方程 ${ }^{[27]}$ 换算. 本文中的生物量皆为湿重.

\section{5 生物多样性指数的计算}

浮游甲壳动物的生物多样性采用 Shannon-Wiener 生物多样性指数 $(H)$ 表征, 计算公式为:

$$
H=-\sum_{i=1}^{s} P_{i} \log _{2} P_{i}, P_{i}=n_{i} / N
$$


式中, $n_{i}$ 表示群落中第 $i$ 物种的个体数, $N$ 表示所有物种的个体数之和, $S$ 表示群落中物种总数, $P_{i}$ 表示第 $i$ 种的个体数占总个体数的比例.

\section{2 结果与分析}

\section{1 太湖 3 个不同生态类型湖区的营养状况}

太湖 3 个不同生态类型湖区中, 湖心区的总氮和总磷年平均浓度最高, 胥口湾最低; 叶绿素 a 浓度在梅 梁湾最高, 胥口湾最低 (表 1 ). 水体理化参数表明, 水体富营养化水平湖心区最高, 梅梁湾次之, 胥口湾最低. 以往的研究中, 梅梁湾的总氮和总磷浓度都高于湖心区 ${ }^{[16]}$, 这表明这几年太湖的富营养水平已发生了改变.

表 12012 年 3 月至 2013 年 2 月太湖不同生态类型湖区理化参数年平均值和范围

Tab. 1 Mean and range of physical-chemical parameters in different ecological areas

in Lake Taihu from March 2012 to February 2013

\begin{tabular}{cccc}
\hline 理化参数 & 梅梁湾 & 胥口湾 & 湖心区 \\
\hline 水温 $/{ }^{\circ} \mathrm{C}$ & $17.9(2.9 \sim 30.2)$ & $18.1(2.4 \sim 31.2)$ & $17.6(3.2 \sim 30.9)$ \\
透明度 $/ \mathrm{cm}$ & $47.0(30.0 \sim 80.0)$ & $35.8(20.0 \sim 40.0)$ & $30.0(10.0 \sim 40.0)$ \\
总氮 $/(\mathrm{mg} / \mathrm{L})$ & $1.563(0.258 \sim 4.438)$ & $1.251(0.244 \sim 2.720)$ & $1.815(0.607 \sim 4.043)$ \\
总磷 $/(\mathrm{mg} / \mathrm{L})$ & $0.106(0.028 \sim 0.303)$ & $0.094(0.009 \sim 0.392)$ & $0.177(0.013 \sim 0.582)$ \\
叶绿素 $\mathrm{a} /(\mu \mathrm{g} / \mathrm{L})$ & $37.557(4.224 \sim 269.010)$ & $7.042(1.267 \sim 12.200)$ & $15.740(5.563 \sim 30.390)$ \\
氨氮 $/(\mathrm{mg} / \mathrm{L})$ & $0.226(0.008 \sim 0.860)$ & $0.179(0.008 \sim 0.992)$ & $0.155(0.007 \sim 0.316)$ \\
$\mathrm{pH}$ & $8.47(7.41 \sim 9.23)$ & $8.25(7.47 \sim 8.70)$ & $8.11(6.91 \sim 8.66)$ \\
溶解氧 $/(\mathrm{mg} / \mathrm{L})$ & $10.57(8.07 \sim 13.22)$ & $10.02(7.14 \sim 13.50)$ & $9.87(7.45 \sim 12.14)$ \\
电导率 $/(\mu \mathrm{S} / \mathrm{cm})$ & $565(363 \sim 767)$ & $522(326 \sim 645)$ & $525(448 \sim 705)$ \\
\hline
\end{tabular}

\section{2 太湖 3 个不同生态类型湖区} 浮游甲壳动物种类组成

整个调查期间, 梅梁湾、胥口 湾和湖心区浮游甲壳动物种类数 分别为 $13 、 11$ 和 11 种. 其中, 桡足 类 6 种,枝角类 7 种. 3 个湖区有 共同种 11 种. 浮游甲壳动物的主 要种类有中华窄腹剑水蚤、简弧 象鼻溞、角突网纹溞和多刺裸腹 溞(表2).

\section{3 太湖 3 个不同生态类型湖区} 浮游甲壳动物密度与生物量

太湖 3 个生态类型湖区浮游 甲壳动物密度有显著差异 $(P<$ $0.01)$, 年平均密度最大值出现在梅 梁湾, 达到 199 ind. /L, 其次是湖心 区, 年平均密度为 150 ind. $/ \mathrm{L}$, 胥口 湾年平均密度最低, 为 $91 \mathrm{ind} . / \mathrm{L}$ (图 1a).
表 22012 年 3 月至 2013 年 2 月太湖不同生态类型湖区 浮游甲壳动物种类分布

Tab. 2 Distribution of crustaceans in different ecological areas in Lake Taihu from March 2012 to February 2013

\begin{tabular}{|c|c|c|c|c|}
\hline & 浮游甲壳动物种类 & 梅梁湾 & 胥口湾 & 湖心区 \\
\hline \multirow[t]{6}{*}{ 桡足类 } & 英勇剑水蚤 (Cyclops strennus) & + & + & + \\
\hline & 跨立小剑水蚤 (Microcyclops varicans) & + & + & + \\
\hline & 指状许水溞( Schmackeria inopinus) & + & + & + \\
\hline & 中华窄腹剑水蚤 (Limnoithona sinensis) & + & + & + \\
\hline & 汤匙华哲水蚤( Sinocalanus dorrii) & + & + & + \\
\hline & 无节幼体 ( Nauplius) & + & + & + \\
\hline \multirow[t]{7}{*}{ 枝角类 } & 透明溞( Daphnia hyalina) & + & + & + \\
\hline & 蚤体溞 (D. pulex) & + & & \\
\hline & 简弧象鼻溞( Bosmina coregoni) & + & + & + \\
\hline & 短尾秀体溞 (Diaphanosoma brachyurum) & + & + & + \\
\hline & 角突网纹溞( Ceriodaphnia cornuta) & + & + & + \\
\hline & 多刺裸腹溞( Moina macrocopa) & + & + & + \\
\hline & 矩形尖额溞(Alona rectangula) & + & & \\
\hline
\end{tabular}

太湖 3 个生态类型湖区浮游甲壳动物生物量也有显著差异 $(P<0.01)$, 年平均生物量最大值出现在梅 梁湾, 为 $1.950 \mathrm{mg} / \mathrm{L}$, 其次是湖心区, 年平均生物量为 $1.557 \mathrm{mg} / \mathrm{L}$, 胥口湾最低, 只有 $0.743 \mathrm{mg} / \mathrm{L}($ 图 $1 \mathrm{~b})$. 


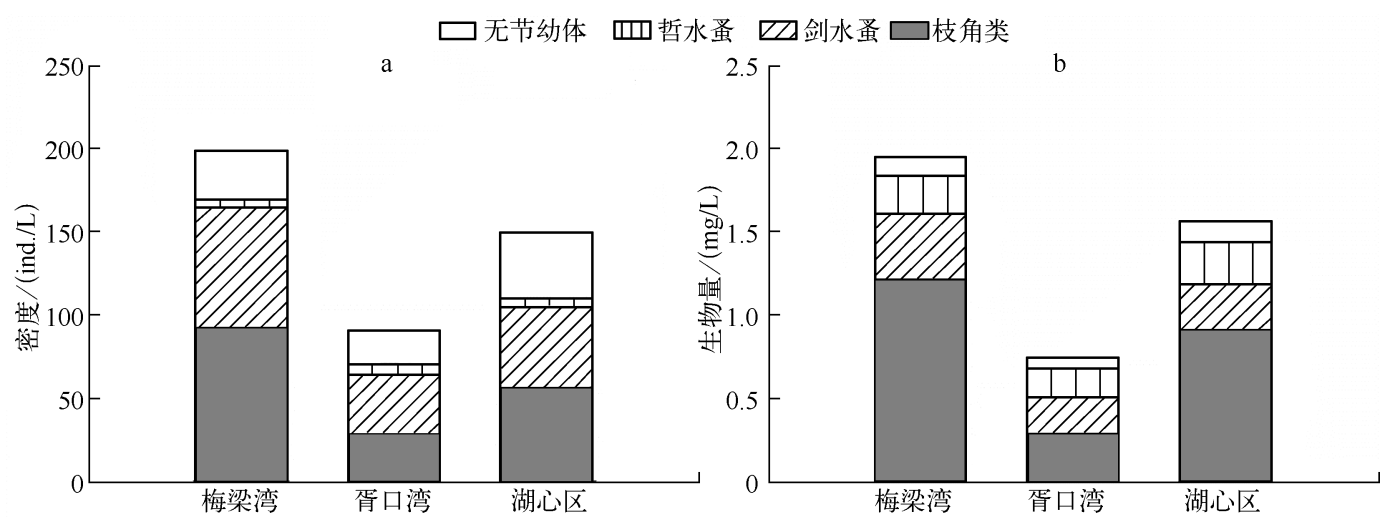

图 1 太湖不同生态类型湖区浮游甲壳动物密度和生物量年平均值

Fig. 1 Annual average abundance and biomass of crustaceans in different ecological areas in Lake Taihu

\section{4 太湖 3 个不同生态类型湖区浮游甲壳动物密度和生物量的季节变化}

梅梁湾、胥口湾和湖心区 3 个生态类型湖区的浮游甲壳动物密度季节变化趋势不同. 梅梁湾的浮游甲 壳动物密度最高值出现在夏季, 胥口湾和湖心区的最高值则出现在秋季, 但 3 个生态类型湖区的浮游甲壳 动物密度最低值都出现在冬季 (图 $2 \mathrm{a}, \mathrm{c}, \mathrm{e}$ ). 梅梁湾的浮游甲壳动物密度在 7 月达到最高值, 为 $648 \mathrm{ind}$. $/ \mathrm{L}$; 胥口湾的最高值出现在 9 月, 为 $304 \mathrm{ind} . / \mathrm{L}$; 而湖心区的最高值出现在 10 月, 为 586 ind. $/$ L. 3 个生态类型湖 区的浮游甲壳动物密度最低值均出现在 2 月, 分别为 $0 、 2 、 2$ ind. $/ \mathrm{L}$.

3 个生态类型湖区浮游甲壳动物生物量季节变化趋势也不同, 梅梁湾、胥口湾和湖心区生物量最高的季 节分别为夏季、秋季和秋季, 而生物量最低值均出现在冬季 (图 $2 \mathrm{~b}, \mathrm{~d}, \mathrm{f}$ ). 3 个生态类型湖区浮游甲壳动物生 物量最高值出现的月份都不同, 梅梁湾、胥口湾和湖心区分别出现在 $7 、 9$ 和 10 月, 最高值分别为 7.599、 3.285 和 $6.577 \mathrm{mg} / \mathrm{L}$; 最低值出现的月份均为 2 月, 分别为 $0 、 0.003$ 和 $0.007 \mathrm{mg} / \mathrm{L}$.

\section{5 太湖 3 个不同生态类型湖区浮游甲壳动物优势种}

在 3 个生态类型湖区中, 浮游甲壳动物的优势种均为中华窄腹剑水蚤和简弧象鼻掻. 在梅梁湾, 中华窄腹

表 3 太湖 3 个湖区浮游甲壳动物密度、 生物量以及生物多样性指数与理化指标的

Pearson 相关性分析

Tab. 3 Pearson's correlation among abundance, biomass, biodiversity index of crustaceans and physicochemical parameters in Lake Taihu

\begin{tabular}{cccc}
\hline \multirow{2}{*}{ 理化参数 } & \multicolumn{3}{c}{ 浮游甲壳动物 } \\
\cline { 2 - 4 } & 密度 & 生物量 & $H$ \\
\hline 水温 & $0.854^{* *}$ & $0.858^{* *}$ & $0.791^{* *}$ \\
透明度 & -0.127 & -0.189 & -0.199 \\
总氮 & -0.153 & -0.100 & 0.014 \\
总磷 & -0.102 & -0.068 & -0.164 \\
叶绿素 a & $0.785^{*}$ & $0.679^{*}$ & 0.268 \\
氨氮 & 0.053 & 0.125 & 0.173 \\
pH & 0.537 & 0.544 & 0.378 \\
溶解氧 & $-0.834^{* *}$ & $-0.836^{* *}$ & $-0.849^{* *}$ \\
电导率 & -0.327 & -0.366 & -0.193 \\
\hline
\end{tabular}

* 表示差异显著, $P<0.05$; ** 表示差异极显著, $P<0.01$.
剑水蚤、简弧象鼻溞的年平均密度分别为 $57 、 40$ ind. $/ \mathrm{L}$, 最高值分别出现在 $7 、 8$ 月, 分别为 $302 、 150$ ind. $/ \mathrm{L}$; 在胥口湾, 中华窄腹剑水蚤、简弧象鼻溞的年 平均密度分别为 $25 、 22$ ind. / L , 分别在 7、9 月达到最 高值, 分别为 $92 、 90$ ind. $/ \mathrm{L}$; 在湖心区, 中华窄腹剑水 蚤、简弧象鼻溞的年平均密度分别为 $37 、 22 \mathrm{ind} . / \mathrm{L}$, 最高值分别出现在 $9 、 10$ 月, 分别为 $146 、 82$ ind. $/ \mathrm{L}$ (图 3).

\section{6 太湖 3 个不同生态类型湖区浮游甲壳动物生物 多样性}

在 3 个生态类型湖区中, 浮游甲壳动物 ShannonWiener 生物多样性指数 $(H)$ 湖心区略高于胥口湾, 其中, 湖心区的生物多样指数为 1.061 , 胥口湾为 1.001 , 梅梁湾最低, 为 0.950 .

2.7 太湖 3 个不同生态类型湖区浮游甲壳动物密度、 生物量和生物多样性指数与理化指标的相关性 分析

Pearson 相关分析表明 (表 3), 浮游甲壳动物密 
王 颖等:太湖不同生态类型湖区浮游甲壳动物群落结构季节变化比较
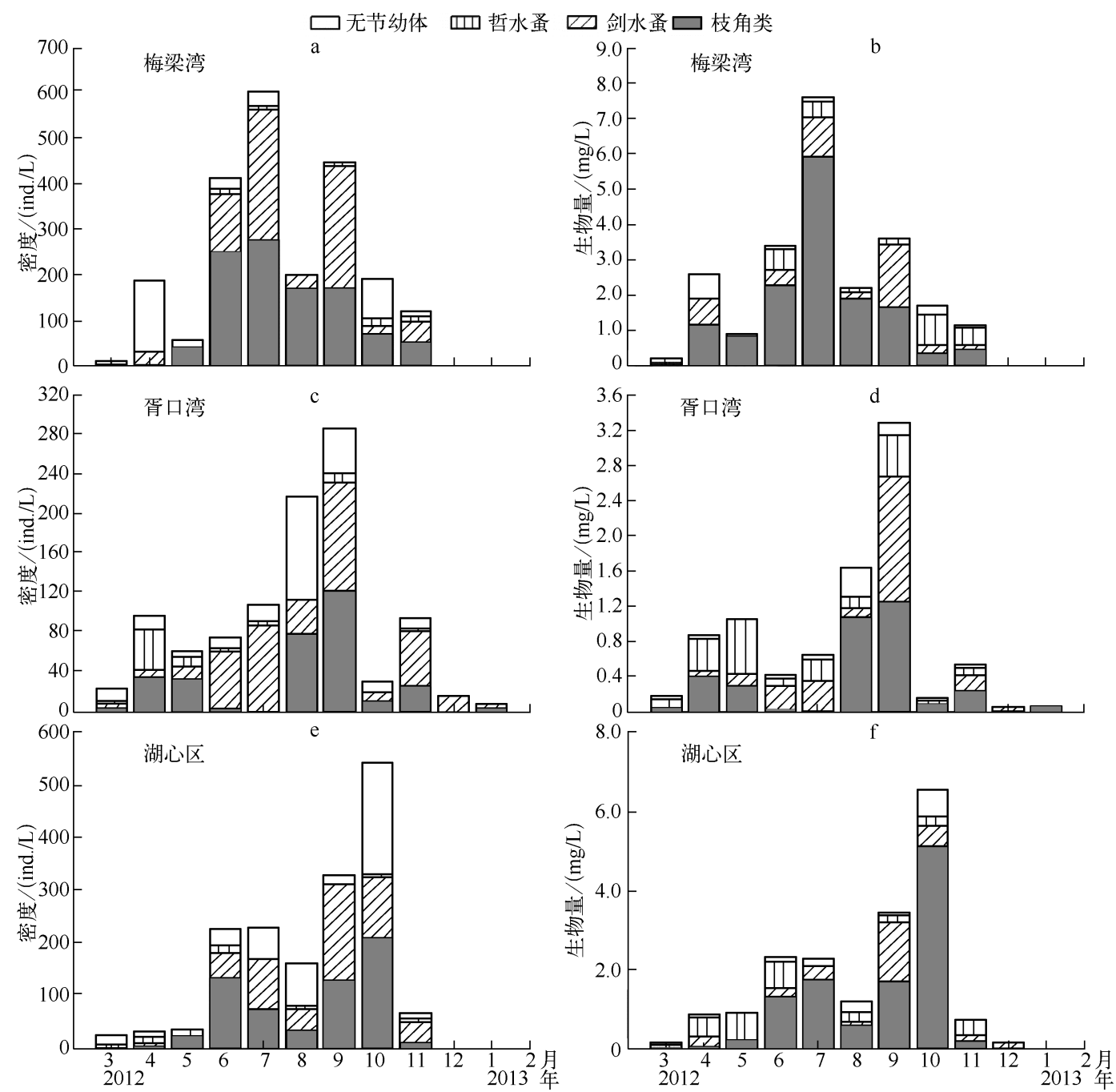

图 22012 年 3 月至 2013 年 2 月太湖不同生态类型湖区浮游甲壳动物密度和生物量的季节变化

Fig. 2 Seasonal variation of abundance and biomass of crustaceans in different ecological areas in Lake Taihu from March 2012 to February 2013
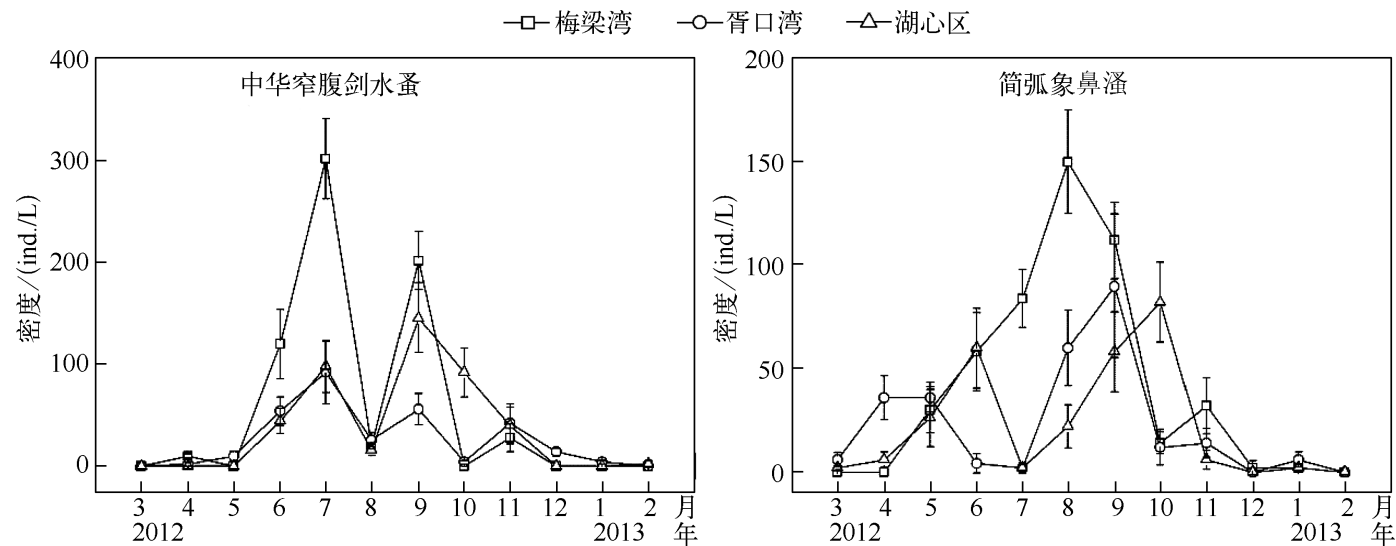

图 32012 年 3 月至 2013 年 2 月太湖不同生态类型湖区浮游甲壳动物优势种密度的季节变化

Fig. 3 Seasonal variation of abundance of dominant crustaceans species in different ecological areas in Lake Taihu from March 2012 to February 2013 
度、生物量和生物多样性指数均与水温呈极显著正相关 $(P<0.01)$, 相关系数 $r$ 分别为 $0.854 、 0.858$ 和 0.791 ; 且均与溶解氧呈极显著负相关 $(P<0.01)$, 相关系数 $r$ 分别为 $-0.834 、-0.836$ 和 -0.848 . 浮游甲壳 动物密度和生物量均与叶绿素 $\mathrm{a}$ 浓度呈显著正相关 $(P<0.05)$, 相关系数 $r$ 分别为 0.785 和 0.679 . 浮游甲壳 动物密度、生物量和生物多样性指数与透明度、总氮、总磷、氨氮、 $\mathrm{pH}$ 和电导率的相关性不显著 $(P>0.05)$.

\section{3 讨论}

梅梁湾、胥口湾和湖心区浮游甲壳动物种类数分别为 $13 、 11$ 和 11 种. 与以往太湖有关浮游甲壳动物的 研究相比, 本研究中浮游甲壳动物的种类数较以前有所减少, 1951-1952 年的研究发现, 太湖中枝角类有 30 种及 1 变种 ${ }^{[28]}, 1981$ 年太湖中发现浮游甲壳动物 39 种 ${ }^{[29]}, 2003-2004$ 年 Yang 等 ${ }^{[16-17]}$ 发现太湖有浮游甲 壳动物 17 种, 2006-2007 年浮游甲壳动物有 16 种, 本研究调查时间为 2012-2013 年,太湖 3 个生态湖区共 发现浮游甲壳动物 13 种, 该结果也表明太湖长期的水体富营养降低了浮游甲壳动物的种类多样性. 而且与其他 富营养湖泊相比, 太湖的浮游甲壳动物种类较少, 王风娟等 ${ }^{[30]}$ 在 2005- 2006 年对巢湖的研究发现浮游甲壳动 物有 46 种, 而鲁敏等 ${ }^{[31]}$ 在 1997-1998 年对武汉东湖的研究发现浮游甲壳动物有 26 种, 这说明太湖相对这 2 个富营养湖泊来说, 其浮游甲壳动物种类多样性要低. 而与富营养化不严重的湖泊相比, 太湖的浮游甲壳 动物种类处于中间水平, 王金秋等 ${ }^{[32]}$ 研究发现, 1999 年鄱阳湖共有浮游甲壳动物 30 种, 比太湖种类多; 但 太湖的浮游甲壳动物种类要比洞庭湖多, 曾春芳等 ${ }^{[33]}$ 在 2005 年只发现浮游甲壳动物 11 种.

本研究太湖 3 个不同生态类型湖区的浮游甲壳动物优势种均为中华窄腹剑水蚤和简弧象鼻溞, 这可能 与以下因素有关. 鱼类捕食是影响浮游甲壳动物群落结构的重要因素之一 ${ }^{[34]}$. 鱼类对大型浮游甲壳动物的 捕食会导致小型浮游甲壳动物和轮虫在浮游甲壳动物群落中占优势 ${ }^{[35-37]}$. 在太湖, 魰是优势鱼类, 2006 年其 产量占鱼类总产量的 $60.2 \%{ }^{[38]}$, 银鱼也是太湖重要的鱼类之一, 2006 年其产量占鱼类总产量的 $1.2 \%$, 魰和 银鱼都以浮游甲壳动物为主要食物, 其中枝角类占鲚食物的 $80 \%$, 而银鱼的食物中超过 $70 \%$ 为桡足类, 鲚对 大型浮游甲壳动物表现出很强的选择性捕食, 而对小型的浮游甲壳动物如象鼻溞则表现出主动回避或随机 选择 ${ }^{[39]}$, 这种选择性捕食可能是导致太湖 3 个生态类型湖区均以小型浮游甲壳动物 (如中华窄腹剑水蚤和 简弧象鼻溞) 为优势种的原因之一. 鱼类对大型浮游甲壳动物的选择性捕食在其它湖泊也有报道 ${ }^{\left[{ }^{[6]}\right.}$.

太湖 3 个不同生态类型湖区中, 梅梁湾浮游甲壳动物年平均密度最大, 其次是湖心区, 胥口湾年平均密 度最低. 食物是调节浮游甲壳动物群落结构的重要因素之一 ${ }^{[40]}$. 梅梁湾属于典型的藻型湖泊, 夏季和秋季梅 梁湾存在大量的蓝藻水华, 虽然蓝藻水华不能被浮游甲壳动物直接牧食, 但蓝藻死亡后产生的大量有机碎 屑以及滋生的大量细菌和原生动物可作为浮游甲壳动物的食物, 所以, 梅梁湾较高的叶绿素 $\mathrm{a}$ 浓度 (平均为 $37.557 \mu \mathrm{g} / \mathrm{L}$ ) 可以解释为什么梅梁湾的浮游甲壳动物密度最高. 湖心区属于强扰动湖区, 强烈的风浪扰动 会使沉积物再悬浮, 沉积物中的营养盐释放到水体中, 有利于藻类的生长, 但强烈的扰动会降低水体透明 度, 不利于藻类进行光合作用, 所以湖心区的叶绿素 a 浓度 $(15.740 \mu \mathrm{g} / \mathrm{L})$ 要低于梅梁湾 $(37.557 \mu \mathrm{g} / \mathrm{L})$. 胥 口湾有大量的沉水植物, 属于典型的草型湖泊. 水生高等植物通过吸收氮、磷 ${ }^{[41]}$, 减少了浮游植物对氮、磷营 养盐的获取; 水生高等植物通过向水体中分泌某种有机物质 ${ }^{[42-44]}$, 抑制浮游植物获得光照 ${ }^{[45]}$; 另外水生高等 植物通过降低底泥的扰动 ${ }^{[46]}$ 减少了底泥向水体中释放营养盐, 间接抑制浮游植物的生长, 降低其密度和生 物量, 因此胥口湾浮游植物较少, 叶绿素 a 浓度 (平均为 $7.042 \mu \mathrm{g} / \mathrm{L}$ ) 最低, 间接反映了浮游植物的含量在 3 个生态湖区中最低. 浮游甲壳动物主要以浮游植物为食, 相关分析也表明, 浮游甲壳动物密度和生物量与叶 绿素 a 浓度呈显著正相关. 因此, 食物密度的不同是太湖 3 个不同生态类型湖区浮游甲壳动物密度和生物量 不同的重要原因之一.

\section{4 结论}

本研究结果表明, 虽然太湖 3 个不同生态类型湖区浮游甲壳动物群落结构基本相同, 但浮游甲壳动物 密度和生物量差异较大, 小型鱼类 (如鲚和银鱼) 的选择性捕食可能是太湖 3 个生态类型湖区浮游甲壳动物 优势种相同的原因, 而 3 个湖区由于生态类型的差异导致浮游植物密度的不同, 这可能是不同生态类型湖 区浮游甲壳动物密度不同的重要原因. 因此同一湖泊中不同生态类型湖区的浮游甲壳动物会对水体富营养 
产生不同的生态响应.

\section{5 参考文献}

[ 1 ] Bosselmann S, Riemann B. Zooplankton. In: Riemann B, Sondergaard ME eds. Carbon dynamics of eutrophic temperate lakes. Amsterdam: Elsevier Science Publisher, 1986:199-235.

[ 2 ] Sas H, Ahlgren I. Lake restoration by reduction of nutrient loading: expectations, experiences, and extrapolations. Sankt Augustin: Academia Verlag Richarz,1989.

[ 3 ] PerssonL, Diehl S, Johansson L et al. Shifts in fish communities along the productivity gradient of temperate lakes-patterns and the importance of size-structured interactions. Journal of Fish Biology,1991,38(2) : 281-293.

[ 4 ] Flores-Burgos J, Sarma SSS, Nandini S. Effect of single species or mixed algal (Chlorella vulgaris and Scenedesmus acutus) diets on the Life Tab. Demography of Brachionus calyciflorus and Brachionus patulus( Rotifera: Brachionidae). Acta Hydrochimica et Hydrobiologica, $2005,33(6)$ : 614-621.

[ 5 ] Kim HW, Hwang SJ, Joo GJ. Crustaceans grazing on bacteria and phytoplankton in a regulated large river (Nakdong River, Korea). Journal of Plankton Research,2000,22 ( 8 ) :1559-1577.

[ 6 ] Jürgens K, Arndt H, Rothaupt KO. Crustaceans-mediated changes of bacterial community structure. Microbial Ecology, $1994,27: 27-42$.

[ 7 ] Jürgens K, Wickham SA, Rothhaupt KO et al. Feeding rates of macrophytoplankton and microcrustaceanson heterotrophic nanoflagellates. Limnology and Oceanography, 1996,41(8):1839-1883.

[ 8 ] Modenutti B, Queimalinos C, Balseiro E et al. Impact of different crustaceans structures on the microbial food web of a South Andean oligotrophic lake. Acta Oecologica,2003,24:289-298.

[ 9 ] 杨宇峰,黄祥飞. 鲢鳙对浮游甲壳动物群落结构的影响. 湖泊科学, 1992,4(3): 78-86.

[10 ] Robert JR, Uwe K. Effects of a filter-feeding fish [ silver carp,Hypophthalmichthys molitrix (val. ) ] on phyto and crustaceans in a mesotrophic reservoir: results from an enclosure experiment. Freshwater Biology,2002,47(12):2337-2344.

[11] Pace ML. An empirical analysis of zooplankton community size structure across lake trophic gradients. Limnology and Oceanography, 1986,31(1) : 45-55.

[12] Auer B, Elzer U, Arndt H. Comparison of pelagic food webs in lakes along a trophic gradient and with seasonal aspects: influence of resource and predation. Journal of Plankton Research,2004,26(6) :697-709.

[13] 王金秋, 吴建平,於燕斌等. 春秋两季鄱阳湖浮游甲壳动物的编目, 数量分布与变动. 湖泊科学, 2003, 15 (4): 345-350。

[14] 王凤娟, 胡子全, 汤 洁等. 用浮游甲壳动物评价巢湖东湖区的水质和营养类型. 生态科学, 2006, 25 (6)： 550-553.

［15］王兆群,张宁红,张 咏等. 洪泽湖水质富营养化评价. 环境监控与预警, 2010, 2(6): 31-35.

[16] Yang GJ, Qin BQ, Tang XM et al. Characterization of crustaceans communities in waters with different eutrophic states in a large, shallow, eutrophic freshwater lake (Lake Taihu, China). Fresenius Environmental Bulletin, 2012, 21(3) : 534 542.

[17] Yang GJ, Zhong C, Pan H. Comparative studies on seasonal variations of metacrustaceans in waters with different eutrophic states in Lake Taihu. Environmental Monitoring and Assessment, 2009, 150(1/2/3/4) : 445-453.

[18] Yang GJ, Qin BQ, Tang XM et al. Contrasting crustaceans communities of two bays of the large, shallow, eutrophic Lake Taihu, China: Their relationship to environmental factors. Journal of Great Lakes Research, 2012 ,38:299-308.

[19] Chen YW, Qin BQ, Teubner K et al. Long term dynamics of phytoplankton assemblages: Microcystis domination in Lake Taihu, a large shallow lake in China. Journal of Plankton Research,2003, 25 (4) :445-453.

[20］金相灿,屠清瑛. 湖泊富营养化调查规范. 北京: 中国环境科学出版社, 1990.

[21] 章宗涉,黄祥飞. 淡水浮游生物研究方法. 北京:科学出版社, 1991.

[22］沈嘉瑞. 中国动物志 - 节肢动物门. 甲壳纲 - 淡水桡足类. 北京: 科学出版社, 1979 .

[23] 蒋䃞治,堵南山. 中国动物志 . 淡水枝角类. 北京: 科学出版社, 1979.

[24] 王家辑. 中国淡水轮虫志. 北京: 科学出版社, 1961 .

[25] 诸葛燕. 中国典型地带轮虫的研究 [学位论文]. 武汉: 中国科学院水生生物研究所, 1997. 
[26] 陈雪梅. 淡水桡足类生物量的计算. 水生生物学集刊, 1981, 7(3) :398-408.

[27] 黄祥飞,胡春英. 淡水常见枝角类体长一体重回归方程式. 见: 甲壳动物学会编. 甲壳动物学论文:第 1 辑. 北京:科 学出版社, 1986: 147-157.

[28］蒋览治.五里湖的枝角类. 水生生物学集刊, 1955,2: 97-114.

[29] 鲍建平, 陈 辉. 太湖的浮游动物. 淡水渔业, 1983,6: 33-38.

[30］王风娟,胡子全, 汤 洁等. 用浮游动物评价巢湖东湖区的水质和营养类型. 生态科学, 2006,25 (6) : 550-553.

[31] 鲁 敏,谢 平. 武汉东湖后湖区浮游甲壳动物群落结构的研究. 水生生物学报,2002,26(2):123-129.

[32] 王金秋, 吴建平, 於燕斌等. 春秋两季鄱阳湖浮游动物的编目, 数量分布与变动. 湖泊科学, 2003, 15(4): 345-350.

[33］曾春芳,黄向荣,李小玲. 南洞庭湖浮游生物资源调查. 内陆水产, 2007, (1) : 24-26.

[34] Brooks JL, Dodson SI. Predation, body size, and composition of plankton. Science, 1965 ,150 (3692) :28-35.

[35] Korponai J, Matyasl K, Paulovits G et al. The effect of different fish communities on the cladoceran plankton assemblages of the Kis Balaton Reservoir, Hungary. Hydrobiologia,1997,360 (1/2/3) : 211-221.

[36] Makarewicz JC. Trophic interactions: changes in phytoplankton community structure coinciding with alewife introduction. Verh. Internat. Verein Limnology,2001,127:1780-1786.

[37] Xie P, Yang YF. Long-term changes of a copepod community (1957-1996) in a subtropical Chinese lake densely stocked with planktivorous filter-feeding silver and bighead carp. Journal of Plankton Research, 2000 ,22 (9) : 1757-1778.

[38］何 俊,谷孝鸿,白秀玲. 太湖渔业产量和结构变化及其对水环境的影响. 海洋湖沼通报,2009,(2):143-150.

[39] 刘恩生, 吴林坤, 曹 萍等. 太湖鱼类渔获量和优势种年龄组成的变化规律及下行效应分析. 安徽农业大学学报, $2005,32(4)$ : $471-477$.

[40 ] Sommer U. Plankton ecology : Succession in plankton communities. Berlin: Springer-Verlag, 1989.

[41] Engelhardt KAM, Ritchie ME. Effects of macrophyte species richness on wetland ecosystem functioning and serveces. $N a$ ture, $2001, \mathbf{4 1 1}: 687-689$.

[42] Jasser I. The influence of macrophytes on a phytoplankton community in experimental conditions. Hydrobiologia,1995, 306 : 21-32.

[43 ] Dai M, Ni LY, Xie P et al. Experimental studies on the effects of submersed macrophytes on the eutrophication of lake water using large-sized enclosures. Acta Hydrobiologica Sinica, 1999,23(2) :97-101.

[44] 杨清心. 富营养水体中沉水植物与浮游藻类相互竞争的研究. 湖泊科学, 1996, 8 (增刊) : 17-24.

[45] Søndergaard M, Moss B. Impact of submerged macrophytes on phytoplankton in shallow freshwater lakes. In: Jeppesen E, Søndergaard M, Sondergarrd M eds. The structuring role of submerged macrophytes in lakes. New York: Springer, 1998: 115-132 .

[46] Ogilvie BG, Mitchell SF. Does sediment resuspention have persistent effects on phytoplankton? Experimental studies in three shallow lakes. Freshwater Biology, 1998,40:51-63. 